\title{
Efficacy of Zinc Sulfate as an Add-on Therapy to Risperidone Versus Risperidone Alone in Patients With Schizophrenia: A Double-Blind Randomized Placebo-Controlled Trial
}

\author{
Mehran Mortazavi, Davood Farzin, ${ }^{1,2}$ Mehran Zarhghami, ${ }^{1,{ }^{*}}$ Seyed Hamzeh Hosseini, ${ }^{1,3}$ Par- \\ isa Mansoori, ${ }^{1}$ and Gholamreza Nateghi ${ }^{1,3}$ \\ ${ }_{2}^{1}$ Psychiatry and Behavioral Sciences Research Center, Addiction Institute, Mazandaran University of Medical Sciences, Sari, IR Iran \\ ${ }_{3}^{2}$ Department of Pharmacology, School of Medicine, Mazandaran University of Medical Sciences, Sari, IR Iran \\ ${ }^{3}$ Department of Psychiatry, School of Medicine, Mazandaran University of Medical Sciences, Sari, IR Iran \\ ${ }^{*}$ Corresponding author: Mehran Zarhghami, Department of Psychiatry, Zare Hospital, Taravat Street, Neka Road, Sari, IR Iran. Tel: +98-1133285569, Fax: +98-1133285109, \\ E-mail:mzarghami@mazums.ac.ir
}

Received: June 21, 2014; Revised: July 24, 2014; Accepted: February 7, 2015

\begin{abstract}
Background: Zinc can modulate fast-excitatory transmission, facilitate the release of amino butyric acid and potentiate nicotinic acetylcholine receptors. There are also emerging evidences discussing the implication of these neurotransmitters in pathophysiology of schizophrenia.

Objectives: The purpose of this study was to evaluate the efficacy of Zn sulfate as an add-on therapy in the treatment of schizophrenia in a 6-week, double-blind and placebo-controlled trial.

Patients and Methods: Eligible participants were 30 inpatients with schizophrenia according to the Diagnostic and Statistical Manual of Mental Disorders, Fourth Edition, Text Revision criteria. Patients were randomly allocated into two equal groups; one group of patients received risperidone $6 \mathrm{mg} /$ day plus capsules of Zn sulfate (each containing $50 \mathrm{mg}$ elemental Zn) three times a day and another group received risperidone $6 \mathrm{mg} /$ day plus placebo. The Positive and Negative Syndrome Scale (PANSS) was applied to assess the psychotic symptoms and aggression risk at baseline, week 2, 4 , and 6 of the study.

Results: The results of this study showed that both protocols significantly decreased the scores on all subscales of the PANSS and supplemental aggression risk subscale as well as PANSS total score over the study. However, this improvement was significantly higher in Zn sulfate receiving group compared to the placebo group. No major clinical side-effects were detected.

Conclusions: It may be concluded that $Z n$ is an effective adjuvant agent in the management of patients with schizophrenia.
\end{abstract}

Keywords: Risperidone; Scale; Schizophrenia; Syndrome; Zinc

\section{Background}

Schizophrenia, affecting around $1 \%$ of the population, is a severe disorder involving chronic or recurrent psychosis and long-term deterioration in functional capacity (1). The characteristic onset of schizophrenia in early adulthood, its lifelong course, and debilitating symptoms, plus its high burden on caregivers and the society make it one of the most disabling and economically catastrophic disorders (1). Despite the improvement of antipsychotic medications, as the main-stay of treatment for patients with schizophrenia, the symptom response is not always optimal, side-effects are frequent, and treatment adherence is often poor (2-4). Therefore, still a large number of studies are ongoing for identifying new drugs of different classes that may be effective in the treatment of schizophrenia (2).

Zinc $(\mathrm{Zn})$ is the second most abundant trace element in the body after iron (5). It is essential for over 300 process- es such as enzymatic catalysis, gene transcription, gene expression, DNA replication, protein synthesis, tissue repair, and hormonal storage $(6,7)$. Zinc is also introduced as an antioxidant element $(5,8)$. It is required for development of the brain and also for its function; Zn deficiency can cause neuronal damage (9-11). While $\mathrm{Zn}$ deficiency is reported in patients with Alzheimer's Disease (AD), cognitive improvement has also been demonstrated in these patients after supplementation with $\mathrm{Zn}$ in some preliminary studies (11). Some studies, however, few in number, have also shown the efficacy of $\mathrm{Zn}$ in improvement of Attention Deficit Hyperactivity Disorder (ADHD) in children and adolescents (12-14). Antidepressant effects of Zn have also been reported in a number of experimental and some clinical studies $(15,16)$. Moreover, effects of adjuvant Zn therapy in the treatment of Obsessive-Compulsive Disorder (OCD) have been reported as well (6). Zinc is

Copyright (C) 2015, Mazandaran University of Medical Sciences. This is an open-access article distributed under the terms of the Creative Commons Attribution-NonCommercial 4.0 International License (http://creativecommons.org/licenses/by-nc/4.0/) which permits copy and redistribute the material just in noncommercial usages, provided the original work is properly cited. 
a cofactor for the metabolism of different neurotransmitters (13). There is growing the body of evidence implicating over activation of N-Methyl-D-aspartate (NMDA) receptors in the pathophysiology of schizophrenia $(17,18)$. Moreover, Zn can modulate fast excitatory transmission by a number of mechanisms (19), suppress the increase in extracellular glutamate (19), and inhibit NMDA receptors (16). It can also facilitate the release of Gamma-Amino Butyric Acid (GABA) $(6,19,20)$. Evidences of GABAergic involvement in the pathophysiology of schizophrenia have also been discussed in several studies (21-23). Furthermore, it is known that $\mathrm{Zn}$ potentiates nicotinic acetylcholine receptors (24). There are also many findings implying cholinergic dysfunction in schizophrenia $(25,26)$.

In one study, the concentration of $\mathrm{Zn}$ in scalp hair of patients with schizophrenia was significantly lower than that in healthy volunteers (27). Reduced serum Zn levels have also been reported in patients with schizophrenia (28). Zinc supplements are commonly used to alleviate a number of conditions, including $\mathrm{Zn}$ deficient states, such as diarrhea, age-related macular degeneration, and wound healing (5). To the best of our knowledge, thus far, the efficacy of $\mathrm{Zn}$ in the treatment of schizophrenia has not been investigated in clinical trials.

\section{Objectives}

The purpose of the present study was to assess the efficacy of Zn sulfate as an adjuvant therapy in the treatment of schizophrenia in a 6-week, double-blind, and placebocontrolled trial.

\section{Patients and Methods}

\subsection{Trial Design}

This randomized, double-blind, placebo-controlled trial was undertaken in Zare Psychiatric Hospital affiliated to the Mazandaran University of Medical Sciences in Sari City, Iran. This trial is registered with the Iranian Clinical Trials Registry (IRCT registration number: $138801241457 \mathrm{~N} 3$ ). The trial was performed in accordance with the ethical standards laid down in the 1995 Declaration of Helsinki (as revised in Edinburgh 2000). All patients and their legally authorized representatives were informed that they could withdraw from the experiment at any time. All of them signed an informed consent form prior to their inclusion in the study. The protocol was approved by the appropriate Ethics Committee on human experimentation of the Mazandaran University of Medical Sciences.

\subsection{Participants}

All participants were inpatients, in the active phase of the disorder, who met Diagnostic and Statistical Manual of Mental Disorders, Fourth Edition, Text Revision (DSMIV-TR) criteria for schizophrenia. All inpatients were considered as potential study population. A minimum score of 80 on the Positive and Negative Syndrome Scale (PANSS) was required for entering the study. Complete blood count, liver enzymes, and creatinine tests, plus electrocardiography were undertaken at baseline. In addition, a urine test was performed to detect morphine and/or cannabis in urine samples of the patients at baseline. The exclusion criteria included any severe medical conditions (e.g. cardiovascular, renal, hepatic, pulmonary, metabolic, endocrine diseases, or immune system disorders), active peptic ulcer, any clinically significant neurological disorder, current or previous history of psychiatric disorders other than schizophrenia, current substance use or history of substance dependency, history of allergy to $\mathrm{Zn}$ or multidrug reaction, taking any medication during the study (except for risperidone, trihexyphenidyl, and lorazepam). Pregnant or lactating women and those of reproductive age without using at least one medically accepted mean of birth control were also excluded. A total of 42 patients were recruited during their hospital stay. Three of them were not eager to enter the trial, and nine other patients excluded due to different conditions including four with the history of drug dependency, two due to abnormal liver enzyme levels, one due to cardiac arrhythmias, one having blood in the urine sample, and another patient who had skin sensitivity. Thirty of the screened patients $($ male/female $=28 / 2$, age range of $18-65$ year old) who met the inclusion criteria and did not meet the exclusion criteria of the trial entered the study.

\subsection{Interventions}

The patients did not receive antipsychotics from a week prior to entering the trial or depot antipsychotics at least 2 months before the study. Risperidone (produced by Sobhan Pharmaceutical Company) was administered in all patients as their standard antipsychotic treatment. It was started with $1 \mathrm{mg}$ twice daily and titrated up to 6 $\mathrm{mg} /$ day in all patients during the week. Participants were randomly allocated into two equal groups $(n=15)$; to one group received risperidone $6 \mathrm{mg} /$ day plus capsules of Zn sulfate $220 \mathrm{mg}$ (each containing $50 \mathrm{mg}$ elemental $\mathrm{Zn})$ three times a day and another group received risperidone $6 \mathrm{mg} /$ day plus identical placebo capsules three times a day for 6 weeks. Placebo capsules were prepared in the pharmaceutical sciences laboratory of pharmacy school, Mazandaran University of Medical Sciences. Patients also received trihexyphenidyl if they faced extrapyramidal symptoms and they received lorazepam in case of agitation or insomnia.

\subsection{Outcomes}

The PANSS was applied to assess the psychotic symptoms at baseline and week 2, 4, and 6 of the study by a trained third-year resident of psychiatry. The PANSS is a common scale in the assessment of schizophrenia including 30 items, which measures both positive and negative 
symptoms, as well as general psychopathology by means of a semistructured patient interview. Intensity of each item will be identified by scoring from 1 to 7 in a manner that more severe symptoms get higher scores (29). The rater used standardized instructions in the use of PANSS. The PANSS supplemental aggression risk subscale was also used to evaluate the aggression risk in patients at the same times that the PANSS was applied (30). The mean decrease in PANSS score from baseline was used as the main outcome measure of response of schizophrenia to treatment. There was no significant difference in psychotic symptoms of two groups of patients according to the PANSS scores at baseline $(\mathrm{P}>0.05)$.

\subsection{Safety}

We were aware of $\mathrm{Zn}$ sulfate possible side effects and were looking for them in patients. So far, the only side-effect of $\mathrm{Zn}$ sulfate that has been reported to occur significantly more than placebo is a metallic taste $(14,31)$. Gastrointestinal discomfort (nausea, vomiting, abdominal pain, and diarrhea) has also been reported with the same rate as placebo $(14,31)$. Skin dermatitis caused by the Zn element of dental fillings has been reported before (32). In the present study, side-effects reported either by the patients or the nurses in the psychiatric ward were recorded. Only one patient in Zn sulfate group withdrew from the trial due to generalized maculopapular reaction.

\subsection{Randomization, Allocation Concealment, and Blinding}

The stratified block randomization technique was used in our investigation. Eligible participants were stratified based on age ( $<25,25-45$, or $\geq 45$ years old), gender (male, female), and subtype of schizophrenia (paranoid or nonparanoid). Then, by 1:1 ratio using a computer generated code the patients were assigned to receive either $\mathrm{Zn}$ sulfate or placebo. The assignments were kept in sealed opaque envelopes until data analysis. Throughout the study, a person who administrated the medications, the PANSS rater, and the patients were all blind to the assignments.

\subsection{Statistical Analysis}

For descriptive analysis of data, statistical indicators like mean and standard deviation (SD) were used, and the repeated measure Analysis of Variance (ANOVA) (timetreatment interaction) was used to assess the effects of treatment. Two groups were considered as the betweensubjects factor and four measurements during treatment were considered as the within-subjects factor (time). This was done for positive, negative, general psychopathology subscale, total PANSS, and supplemental aggression risk scores. GraphPad Prism software version 5 (GraphPad Software Inc., California, USA) was used to analyze, graph and present scientific data. Differences with $\mathrm{P}<0.05$ were considered as statistically significant.

\section{Results}

\subsection{Patient Disposition and Characteristics}

From a total of 42 patients screened for the study, 30 cases were randomly allocated into two groups for trial medication (15 patients in each group) (Figure 1).

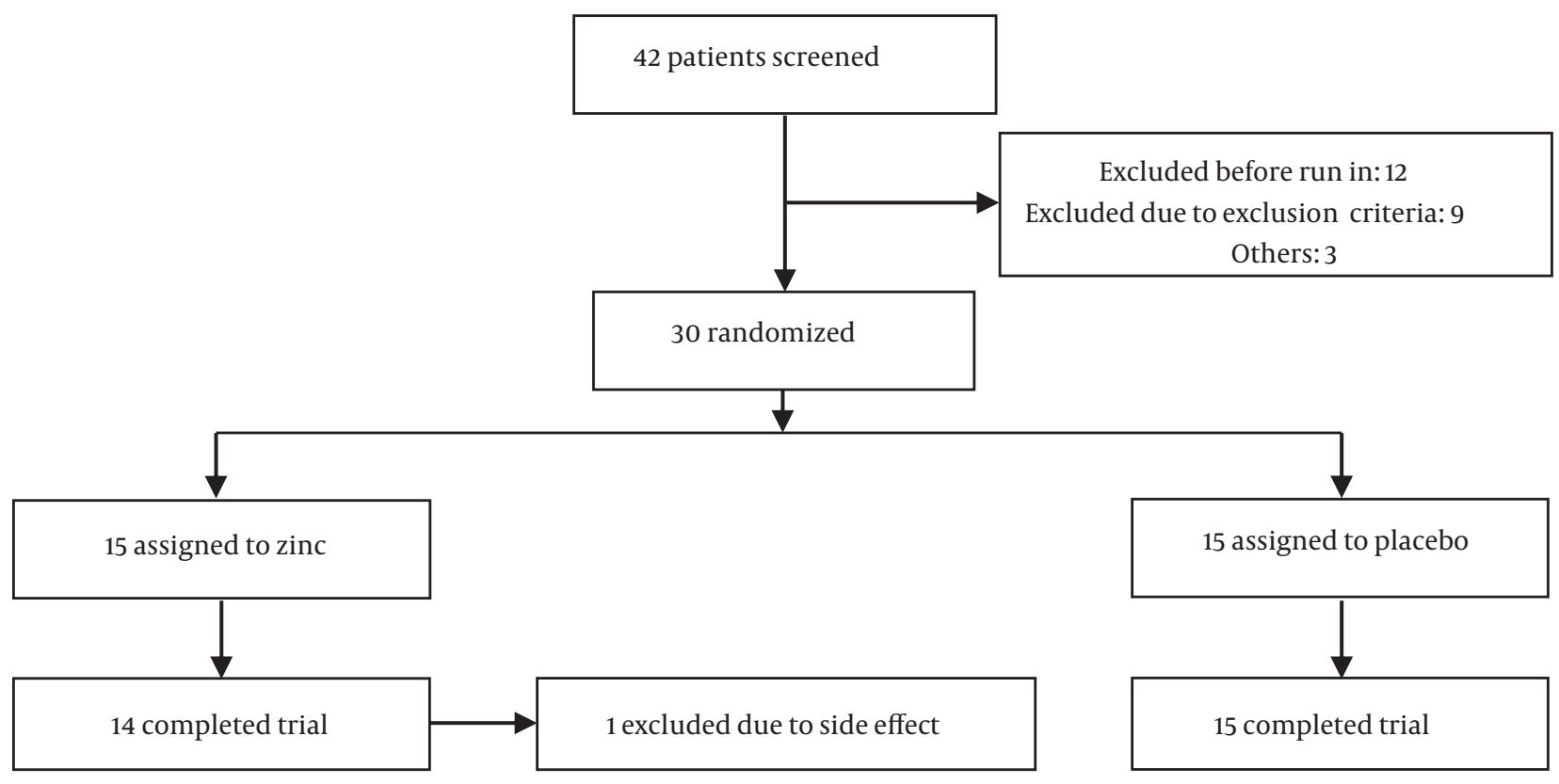

Figure 1. Trial Profile 
No significant difference was found between patients randomly assigned to $\mathrm{Zn}$ or placebo group regarding basic demographic data including age, gender, marital status, level of education, and subgroup of schizophrenia (Table 1).

\subsection{Outcomes}

The mean \pm standard deviation of positive symptoms scale, negative symptoms scale, the general psychopathology scale, total PANSS score, and the supplemental aggression risk subscale of two groups of patients are shown in Table 2. There were no significant differences between the two groups at week 0 (baseline) on positive symptoms on PANSS $(\mathrm{P}=0.55)$, negative symptoms on PANSS $(\mathrm{P}=0.62)$, general psychopathology on PANSS $(\mathrm{P}=$ $0.69)$, and PANSS total score $(\mathrm{P}=0.48)$.

\begin{tabular}{|c|c|c|c|}
\hline Variables & Zinc Group & Placebo Group & PValue \\
\hline Gender & & & 1.00 \\
\hline Male & 14 & 14 & \\
\hline Female & 01 & 01 & \\
\hline Age, $y$ & & & 0.80 \\
\hline$<25$ & 05 & 04 & \\
\hline $24-45$ & 09 & 09 & \\
\hline$>45$ & 01 & 02 & \\
\hline Marital status & & & 0.90 \\
\hline Married & 04 & 04 & \\
\hline Divorced & 03 & 04 & \\
\hline Single & 08 & 07 & \\
\hline Level of education & & & 0.59 \\
\hline Primary & 10 & 11 & \\
\hline High school & 04 & 02 & \\
\hline Higher & 01 & 02 & \\
\hline Subgroup of schizophrenia & & & 1.00 \\
\hline Paranoid & 01 & 01 & \\
\hline Nonparanoid & 14 & 14 & \\
\hline
\end{tabular}

Table 2. Positive and Negative Syndrome Scale Scores in Two Protocols ${ }^{a}$

\begin{tabular}{|c|c|c|c|c|}
\hline & Week 0 & Week 2 & Week 4 & Week 6 \\
\hline \multicolumn{5}{|l|}{ Positive subscale of PANSS ${ }^{b}$} \\
\hline Risperidone + zinc sulfate & $31.27 \pm 3.84$ & $18.13 \pm 2.35$ & $12.93 \pm 2.21$ & $09.86 \pm 2.82$ \\
\hline Risperidone + placebo & $32.13 \pm 4.10$ & $21.20 \pm 3.38$ & $18.80 \pm 4.24$ & $12.87 \pm 4.22$ \\
\hline \multicolumn{5}{|l|}{ Negative subscale of PANSS } \\
\hline Risperidone + zinc sulfate & $32.87 \pm 3.29$ & $18.67 \pm 1.54$ & $12.8 \pm 2.04$ & $9.93 \pm 2.21$ \\
\hline Risperidone + placebo & $33.67 \pm 5.26$ & $20.67 \pm 3.67$ & $18.2 \pm 4.32$ & $13.00 \pm 4.50$ \\
\hline \multicolumn{5}{|l|}{ General psychopathology } \\
\hline Risperidone + zinc sulfate & $70.20 \pm 6.13$ & $46.40 \pm 3.71$ & $33.40 \pm 4.12$ & $24.53 \pm 5.63$ \\
\hline Risperidone + placebo & $69.47 \pm 3.50$ & $45.20 \pm 4.45$ & $40.33 \pm 6.46$ & $27.60 \pm 6.55$ \\
\hline \multicolumn{5}{|l|}{ PANSS total score } \\
\hline Risperidone + zinc sulfate & $147.50 \pm 11.72$ & $91.67 \pm 6.76$ & $66.00 \pm 7.07$ & $49.80 \pm 12.15$ \\
\hline Risperidone + placebo & $149.90 \pm 6.14$ & $96.60 \pm 8.38$ & $85.73 \pm 13.00$ & $60.60 \pm 14.16$ \\
\hline \multicolumn{5}{|l|}{ Risk of aggression } \\
\hline Risperidone + zinc sulfate & $13.30 \pm 3.22$ & $8.60 \pm 1.92$ & $06.86 \pm 1.30$ & $04.80 \pm 1.60$ \\
\hline Risperidone + placebo & $14.60 \pm 1.63$ & $9.53 \pm 1.40$ & $08.53 \pm 1.40$ & $07.33 \pm 1.23$ \\
\hline
\end{tabular}

${ }^{a}$ Data are presented as mean \pm SD

$\mathrm{b}$ Positive and negative syndrome scale. 
Figure 2. Measures of Positive Scale of Positive and Negative Syndrome Scale Scores at Weeks 0, 2, 4, and 6

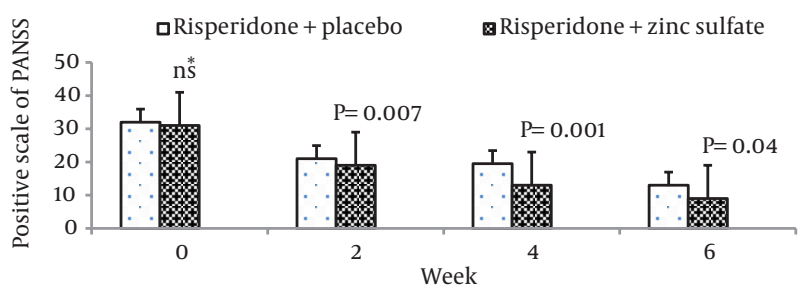

Results are expressed as mean \pm standard deviation. $\mathrm{P}=0.007, \mathrm{P}=0.001, \mathrm{P}$ $=0.040$, different from control groups $\left({ }^{*}\right.$ not significant $)$.

Figure 3. Measures of Negative Scores of Positive and Negative Syndrome Scale at Weeks $0,2,4$, and 6

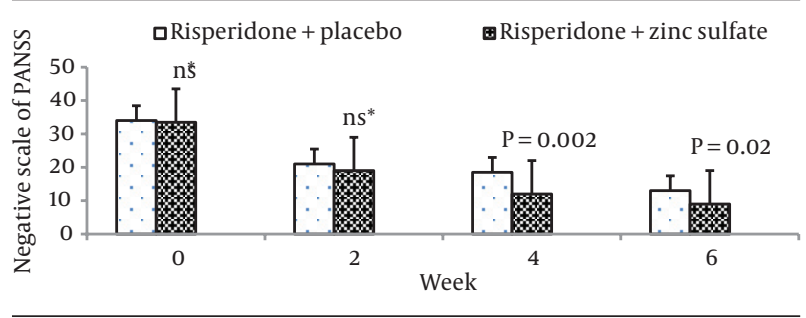

Results are expressed as mean \pm standard deviation. $\mathrm{P}=0.002, \mathrm{P}=0.020$, different from control groups ( ${ }^{*}$ not significant).

Figure 4. Measures of General Psychopathology of Positive and Negative Syndrome Scale Scores at Weeks 0, 2, 4, and 6

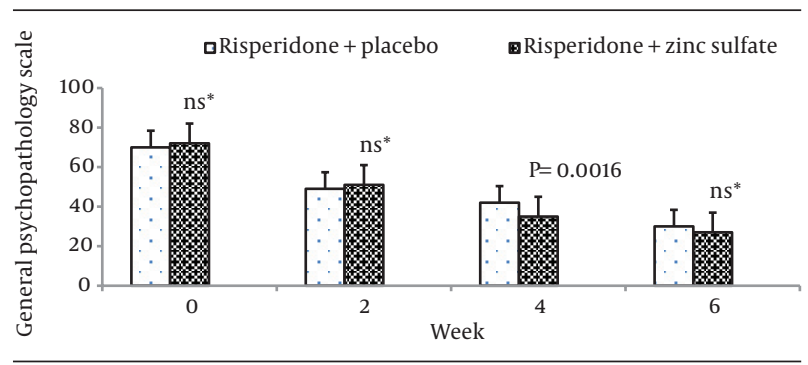

Results are expressed as mean \pm standard deviation. $\mathrm{P}=0.0016$, different from control group ( ${ }^{*}$ not significant).

Figure 5. Measures of Total Positive and Negative Syndrome Scale Scores at Weeks $0,2,4$, and 6

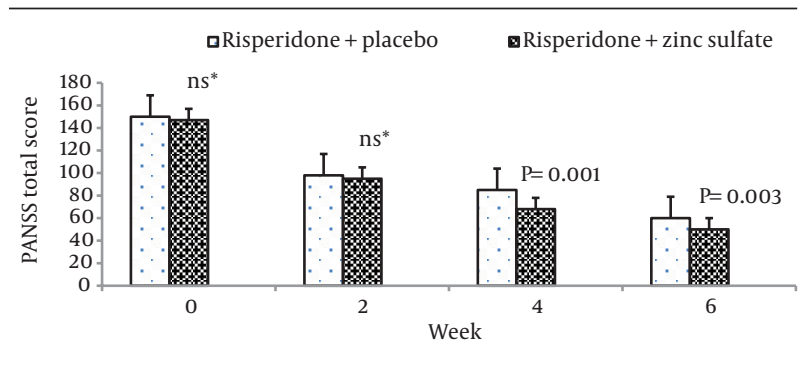

Results are expressed as mean \pm standard deviation. $\mathrm{P}=0.001, \mathrm{P}=0.033$, different from control groups ( ${ }^{*}$ not significant).
Figure 6. Measures of Risk of Aggression Subscale of Positive and Negative Syndrome Scale Scores at Weeks 0, 2, 4, and 6

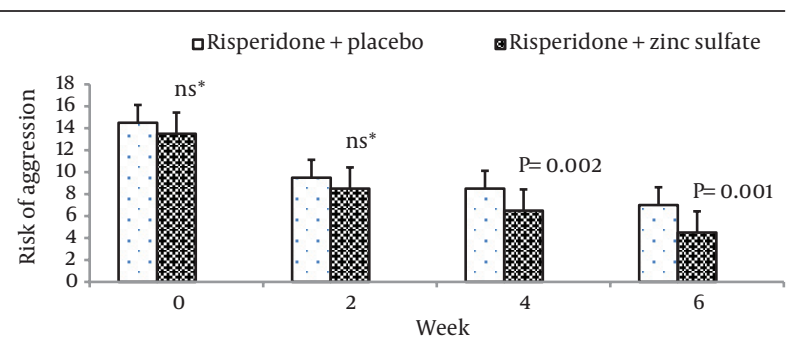

Results are expressed as mean \pm standard deviation. $\mathrm{P}=0.002, \mathrm{P}=0.001$ different from control groups ( ${ }^{*}$ not significant).

Moreover, there was no significant difference between the two groups at baseline regarding risk of aggression $(\mathrm{P}=0.12)$. The differences between the two groups on the positive scale, negative scale, the general psychopathology scale, total PANSS score, and the PANSS supplemental aggression risk subscale scores are demonstrated in Figures $2-6$, respectively.

\section{Discussion}

Schizophrenia is estimated to be the 8th leading cause of disability-adjusted life years worldwide in the age group 15 - 44 years (1). It is characterized by a diverse range of symptoms, including positive symptoms (such as hallucinations and delusions), negative symptoms (such as social withdrawal and diminished affective responsiveness), and cognitive deficits (33). Its treatment involves a combination of psychosocial rehabilitation and pharmacotherapy (3). Despite the improvement of antipsychotics, treatment of schizophrenia is still a big challenge for clinicians $(2,3)$. Thus, several studies are ongoing for identifying drugs of different classes, other than dopamine antagonists, that may enhance the response to antipsychotics, or that may even have efficacy as monotherapy $(2,17,34)$.

The results obtained in the present trial demonstrate that adding $\mathrm{Zn}$ to an atypical antipsychotic regimen is effective in the improvement of symptoms of schizophrenia and risk of aggression in patients with schizophrenia. Both studied groups, treated with risperidone during the 6-week trial, showed a significant improvement on PANSS total score and on its all subscales as well as the supplemental aggression risk subscale. The Zn group had significantly greater improvement in total score of PANSS, positive and negative symptoms, and risk of aggression over the 6-week trial. Baseline characteristics of patients including sex, age, marital status, level of education, and subgroup of schizophrenia did not differ between the groups; thus, cannot explain differences in the therapeutic outcome. To the best of our knowledge, this study was the first double-blind and placebo-controlled clinical trial investigating the efficacy of $\mathrm{Zn}$ in the treatment of schizophrenia. Complementary medicines, such 
as trace element supplements, can be assumed as proper candidates for investigation in chronic psychiatric disorders due to lower risk of side-effects as well as better acceptance among people (35). Zinc is an essential trace element in the body $(6,7)$, which is required for development of the brain and also for its function (9-11). So far, positive effects of supplemental Zn on depression $(15,36$, $37), \mathrm{OCD}(6), \operatorname{ADHD}(14,31)$, and $\mathrm{AD}(11)$ have been reported in other studies.

To the best of our knowledge, there is no report of kinetic interactions between $\mathrm{Zn}$ sulfate and risperidone. This leads us to assume that the therapeutic effect observed by Zn sulfate on symptoms of schizophrenia is likely to result from a pharmacodynamic mechanism. It has been reported that $\mathrm{Zn}$ serves as an endogenous neuromodulator of several important transmitters (19) and this role can be used for explaining its mechanism of action in the improvement of schizophrenia. There is growing the body of evidence implicating glutamatergic system in the pathophysiology of schizophrenia (4, $17,18,38)$. Along with the studies reporting the efficacy of NMDA receptor allosteric agonists at the glycinB site in schizophrenia (4) some scientists have hypothesized the possible efficacy of NMDA antagonists in this disorder $(4,39)$. A preliminary study has even shown the probable efficacy of memantine as a noncompetitive NMDA antagonist in improvement of schizophrenia (39). Also, Zn can modulate fast excitatory transmission by a number of mechanisms (19). It suppresses the increase in extracellular glutamate (19) and inhibits NMDA receptors (16). An ex-vivo study has suggested that low-affinity NMDA receptor antagonists might even interact with dopamine receptors by binding the dopamine transporters (40). Evidences of GABAergic involvement in the pathophysiology of schizophrenia have also been discussed in several studies $(22,23)$. However, a recent meta-analysis did not find significant therapeutic benefits in addition of benzodiazepines to the antipsychotic regimen of schizophrenic patients (41). In a small preliminary randomized trial, selective benzodiazepine acting at the GABAa receptor improved working memory in patients with schizophrenia (22). Although a similar investigation in a greater sample size showed only little benefit of that prodrug, this receptor remains a promising target (42). Moreover, Zn facilitates the release of $\operatorname{GABA}(6,19,20)$ and may improve symptoms of schizophrenia via this mechanism.

It is known that $\mathrm{Zn}$ potentiates nicotinic acetylcholine receptors (24). There are also many findings implying cholinergic dysfunction in schizophrenia $(25,26,43)$. In two preliminary studies, a cholinergic nicotinic partial agonist (25) and muscarinic cholinergic agonist (43) showed some efficacy in improving symptom scores and cognition in patients with schizophrenia, which the results are in line with ours.

The impact of $\mathrm{Zn}$ on improvement of negative symptoms of schizophrenia can also be due to its antidepres- sant implications, which have been reported in previous studies $(15,36,37)$. Zinc also has antioxidant properties ( 5 , 8 ), which can be considered as another explanation for its effectiveness in schizophrenia. There are studies reporting increased production of reactive oxygen or decreased antioxidant protection in patients with schizophrenia that strengthen the hypothesis suggesting the role of excessive free radical production or oxidative stress in the pathophysiology of this disorder (33).

In one study, the concentration of $\mathrm{Zn}$ in scalp hair of schizophrenic patients was significantly lower than that in healthy volunteers (37). Reduced serum $\mathrm{Zn}$ levels have also been reported in patients with schizophrenia (28). However, the extracellular Zn concentration may not be a good indicator of $\mathrm{Zn}$ concentration in the body (19).

In our study, adding Zn to risperidone was effective in reducing aggression. A study demonstrated that mean plasma $\mathrm{Zn}$ values were significantly lower in criminal schizophrenic men compared with noncriminal subjects (44). Another study had also reported that blood copper/ $\mathrm{Zn}$ ratios in assaultive young males were high when compared to a control group of young males with no history of an assaultive behavior (45).

Administration of $220 \mathrm{mg}$ of $\mathrm{Zn}$ sulfate three times a day was well-tolerated, and no major clinical side-effects were detected. However, due to the lack of systematic recording of side-effects during the trial, which should be considered as a shortcoming of this study, there may have been some missed side-effects that were neither reported by our patients nor observed by the nurses. Other limitations of the present study include using only one dose of Zn sulfate, the small number of participants, short period of follow-up, and lack of a plasma Zn concentration that all indicate the need for future studies. In line with our hypothesis, adding Zn to an atypical antipsychotic was particularly effective in the improvement of positive and negative symptoms subscales on PANSS, general psychopathology subscale, and total score of PANSS as well as risk of aggression in patients with schizophrenia.

\section{Authors' Contributions}

Mehran Zarghami designed the study and wrote the protocol. Davood Farzin, Gholamreza Nateghi, and Mehran Mortazavi helped to conceive and design the evaluation. Davood Farzin managed the literature searches and analyses, and undertook the statistical analysis. Mehran Mortazavi helped to literature review and collected the clinical data. Mehran Zarhghami, Davood Farzin, Mehran Mortazavi, Gholamreza Nateghi, Seyed Hamzeh Hosseini and Parisa Mansoori interpreted the clinical data and Parisa Mansoori and Mehran Mortazavi wrote the first draft of the manuscript. All authors contributed to and have approved the final manuscript.

\section{Declaration of interest}

None declared. 


\section{Funding/Support}

This study was supported by a grant from Mazandaran University of Medical Sciences to Prof. Mehran Zarghami (grant no. 8684).

\section{Clinical Trial Registration}

Unique identifier: IRCT138801241457N3.

\section{References}

1. Rossler W, Salize HJ, van Os J, Riecher-Rossler A. Size of burden of schizophrenia and psychotic disorders. Eur Neuropsychopharmacol. 2005;15(4):399-409.

2. Ballon J, Stroup TS. Polypharmacy for schizophrenia. Curr Opin Psychiatry. 2013;26(2):208-13.

3. Priebe S, Savill M, Reininghaus U, Wykes T, Bentall R, Lauber C, et al. Effectiveness and cost-effectiveness of body psychotherapy in the treatment of negative symptoms of schizophrenia--a multicentre randomised controlled trial. BMC Psychiatry. 2013;13:26.

4. Lieberman JA, Papadakis K, Csernansky J, Litman R, Volavka J, Jia $\mathrm{XD}$, et al. A randomized, placebo-controlled study of memantine as adjunctive treatment in patients with schizophrenia. Neuropsychopharmacology. 2009;34(5):1322-9.

5. Saper RB, Rash R. Zinc: an essential micronutrient. Am Fam Physician. 2009;79(9):768-72.

6. Sayyah M, Olapour A, Saeedabad Y, Yazdan Parast R, Malayeri A Evaluation of oral zinc sulfate effect on obsessive-compulsive disorder: a randomized placebo-controlled clinical trial. Nutrition. 2012;28(9):892-5.

7. Ronowska A, Dys A, Jankowska-Kulawy A, Klimaszewska-Lata J, Bielarczyk H, Romianowski P, et al. Short-term effects of zinc on acetylcholine metabolism and viability of SN56 cholinergic neuroblastoma cells. Neurochem Int. 2010;56(1):143-51.

8. Li Y, Zheng Y, Qian J, Chen X, Shen Z, Tao L, et al. Preventive effects of zinc against psychological stress-induced iron dyshomeostasis, erythropoiesis inhibition, and oxidative stress status in rats. Biol Trace Elem Res. 2012;147(1-3):285-91.

9. Mori R, Ota E, Middleton P, Tobe-Gai R, Mahomed K, Bhutta ZA Zinc supplementation for improving pregnancy and infant outcome. Cochrane Database Syst Rev. 2012;7:eCD000230.

10. Sandstead HH. Subclinical zinc deficiency impairs human brain function.J Trace Elem Med Biol. 2012;26(2-3):70-3.

11. Brewer GJ. Copper excess, zinc deficiency, and cognition loss in Alzheimer's disease. Biofactors. 2012;38(2):107-13.

12. Ghanizadeh A, Berk M. Zinc for treating of children and adolescents with attention-deficit hyperactivity disorder: a systematic review of randomized controlled clinical trials. Eur J Clin Nutr. 2013;67(1):122-4.

13. Millichap JG, Yee MM. The diet factor in attention-deficit/hyperactivity disorder. Pediatrics. 2012;129(2):330-7.

14. Akhondzadeh S, Mohammadi MR, Khademi M. Zinc sulfate as an adjunct to methylphenidate for the treatment of attention deficit hyperactivity disorder in children: a double blind and randomized trial [ISRCTN64132371]. BMC Psychiatry. 2004;4:9.

15. Lai J, Moxey A, Nowak G, Vashum K, Bailey K, McEvoy M. The efficacy of zinc supplementation in depression: systematic review of randomised controlled trials. J Affect Disord. 2012;136(12):e31-9.

16. Nikseresht S, Etebary S, Karimian M, Nabavizadeh F, Zarrindast MR, Sadeghipour HR. Acute administration of $\mathrm{Zn}, \mathrm{Mg}$, and thiamine improves postpartum depression conditions in mice. Arch Iran Med. 2012;15(5):306-11.

17. DeLisi LE, Fleischhacker WW. Schizophrenia today: do we know any more and can we treat it better than a decade ago? Curr Opin Psychiatry. 2008;21(2):131-2.

18. Weiser M, Heresco-Levy U, Davidson M, Javitt DC, Werbeloff N, Gershon AA, et al. A multicenter, add-on randomized controlled trial of low-dose d-serine for negative and cognitive symptoms of schizophrenia.J Clin Psychiatry. 2012;73(6):e728-34.
19. Takeda A, Tamano H. Insight into zinc signaling from dietary zinc deficiency. Brain Res Rev. 2009;62(1):33-44

20. Paoletti P, Vergnano AM, Barbour B, Casado M. Zinc at glutamatergic synapses. Neuroscience. 2009;158(1):126-36.

21. Patil ST, Zhang L, Martenyi F, Lowe SL, Jackson KA, Andreev BV, et al. Activation of mGlu2/3 receptors as a new approach to treat schizophrenia: a randomized Phase 2 clinical trial. Nat Med. 2007;13(9):1102-7.

22. Lewis DA, Cho RY, Carter CS, Eklund K, Forster S, Kelly MA, et al. Subunit-selective modulation of GABA type A receptor neurotransmission and cognition in schizophrenia. Am J Psychiatry. 2008;165(12):1585-93.

23. Gonzalez-Burgos G, Fish KN, Lewis DA. GABA neuron alterations, cortical circuit dysfunction and cognitive deficits in schizophrenia. Neural Plast. 2011;2011:723184.

24. Vazquez-Gomez E, Garcia-Colunga J. Neuronal nicotinic acetylcholine receptors are modulated by zinc. Neuropharmacology. 2009;56(6-7):1035-40.

25. Freedman R, Olincy A, Buchanan RW, Harris JG, Gold JM, Johnson $\mathrm{L}$, et al. Initial phase 2 trial of a nicotinic agonist in schizophrenia. Am J Psychiatry. 2008;165(8):1040-7.

26. Lieberman JA, Javitch JA, Moore H. Cholinergic agonists as novel treatments for schizophrenia: the promise of rational drug development for psychiatry. Am J Psychiatry. 2008;165(8):931-6.

27. Rahman A, Azad MA, Hossain I, Qusar MM, Bari W, Begum F, et al. Zinc, manganese, calcium, copper, and cadmium level in scalp hair samples of schizophrenic patients. Biol Trace Elem Res. 2009;127(2):102-8.

28. Farzin D, Mansouri N, Yazdani T. P. 3.a. 002 Elevated plasma copper/zinc ratios in patients with schizophrenia. Eur Neuropsychopharmacology. 2006;16:S364-5.

29. Noorbala AA, Akhondzadeh S, Davari-Ashtiani R, AminiNooshabadi H. Piracetam in the treatment of schizophrenia: implications for the glutamate hypothesis of schizophrenia. J Clin Pharm Ther. 1999;24(5):369-74

30. White L, Harvey PD, Opler L, Lindenmayer JP. Empirical assessment of the factorial structure of clinical symptoms in schizophrenia. A multisite, multimodel evaluation of the factorial structure of the Positive and Negative Syndrome Scale. The PANSS Study Group. Psychopathology. 1997;30(5):263-74.

31. Bilici M, Yildirim F, Kandil S, Bekaroglu M, Yildirmis S, Deger O, et al. Double-blind, placebo-controlled study of zinc sulfate in the treatment of attention deficit hyperactivity disorder. Prog Neuropsychopharmacol Biol Psychiatry. 2004;28(1):181-90.

32. Shimizu T, Kobayashi S, Tanaka M. Systemic contact dermatitis to zinc in dental fillings. Clin Exp Dermatol. 2003;28(6):675-6.

33. Chomette G, Auriol M, Zeitoun R, Mousques T. [Effect of the soft laser on gingival connective tissue. I--Effect on fibroblasts. Histoenzymology and electron microscopy study]. J Biol Buccale. 1987;15(1):45-9.

34. Morozova MA, Beniashvili AG, Lepilkina TA, Rupchev GE. Doubleblind placebo-controlled randomized efficacy and safety trial of add-on treatment of dimebon plus risperidone in schizophrenic patients during transition from acute psychotic episode to remission. Psychiatr Danub. 2012;24(2):159-66.

35. Safarinejad MR. The effects of the adjunctive bupropion on male sexual dysfunction induced by a selective serotonin reuptake inhibitor: a double-blind placebo-controlled and randomized study. BJU Int. 2010;106(6):840-7.

36. Rosa AO, Lin J, Calixto JB, Santos AR, Rodrigues AL. Involvement of NMDA receptors and L-arginine-nitric oxide pathway in the antidepressant-like effects of zinc in mice. Behav Brain Res. 2003;144(1-2):87-93.

37. Siwek M, Dudek D, Paul IA, Sowa-Kucma M, Zieba A, Popik P, et al. Zinc supplementation augments efficacy of imipramine in treatment resistant patients: a double blind, placebo-controlled study. J Affect Disord. 2009;118(1-3):187-95.

38. Paz RD, Tardito S, Atzori M, Tseng KY. Glutamatergic dysfunction in schizophrenia: from basic neuroscience to clinical psychopharmacology. Eur Neuropsychopharmacol. 2008;18(11):773-86.

39. de Lucena D, Fernandes BS, Berk M, Dodd S, Medeiros DW, Pedrini $\mathrm{M}$, et al. Improvement of negative and positive symptoms in 
treatment-refractory schizophrenia: a double-blind, randomized, placebo-controlled trial with memantine as add-on therapy to clozapine. J Clin Psychiatry. 2009;70(10):1416-23.

40. David HN, Ansseau M, Lemaire M, Abraini JH. Nitrous oxide and xenon prevent amphetamine-induced carrier-mediated dopamine release in a memantine-like fashion and protect against behavioral sensitization. Biol Psychiatry. 2006;60(1):49-57.

41. Dold M, Li C, Gillies D, Leucht S. Benzodiazepine augmentation of antipsychotic drugs in schizophrenia: a meta-analysis and Cochrane review of randomized controlled trials. Eur Neuropsychopharmacol. 2013;23(9):1023-33.

42. Buchanan RW, Keefe RS, Lieberman JA, Barch DM, Csernansky JG,
Goff DC, et al. A randomized clinical trial of MK-0777 for the treatment of cognitive impairments in people with schizophrenia. Biol Psychiatry. 2011;69(5):442-9.

43. Shekhar A, Potter WZ, Lightfoot J, Lienemann J, Dube S, Mallinckrodt $\mathrm{C}$, et al. Selective muscarinic receptor agonist xanomeline as a novel treatment approach for schizophrenia. Am J Psychiatry. 2008;165(8):1033-9.

44. Tokdemir M, Polat SA, Acik Y, Gursu F, Cikim G, Deniz O. Blood zinc and copper concentrations in criminal and noncriminal schizophrenic men. Arch Androl. 2003;49(5):365-8.

45. Walsh WJ, Isaacson HR, Rehman F, Hall A. Elevated blood copper zinc ratios in assaultive young males. Physiol Behav. 1997;62(2):327-9. 